\title{
MORFO - ANATOMÍA DE LAS FABACEAS Piptadenia grata (vilca). Caesalpinia spinosa (tara) y Geoffroeae decorticans (CHAÑAR) DE LA PROVINCIA DE TACNA.
}

Responsable : Blga. Yolanda Ibarra Sosa Miembro : Blga. Isabel Ancco Silva

\section{RESUMEN}

Con la finalidad de incrementar el conocimiento cientifico de las fabáceas, se estudió la morfo-anatomía de las especies Acacia visco, Caesalpinia spinosa y Geoffroea decorticans de la provincia de Tacna.

El material fue colectado en los distritos de Tacna, Pocollay, Calana y Pachía de la provincia de Tacna, departamento de Tacna. Se describe la morfologia externa de los órganos vegetativos y reproductores. Para estudiar la anatomia de las plantas se realizaron cortes histológicos en secciones transversales y longitudinales del tallo, raiz y ovario; transversales y superficiales de la hoja, hechos a mano alzada; los cortes fueron teñidos con safranina. Las observaciones se realizaron con ayuda del microscopio óptico, se tomaron fotografias, microfotografias y se realizaron esquemas y mediciones de las muestras las cuales se presentan en figuras, fotografias y cuadros.

Los resultados obtenidos permiten establecer diferencias estructurales externas e internas de las especies estudiadas.

\section{INTRODUCCIÓN}

El estudio de las plantas reviste interés e importancia a causa de las funciones vitales que desempeñan en la ciencia y en la vida del hombre. Dicho estudio puede hacerse con finalidades distintas. Asi, de un árbol u otro vegetal cualquiera podemos estudiar su forma y darnos cuenta que está conformado por una raíz, tallo, hojas, flores, frutos, de los cuales podemos estudiar su forma, estructura, composición quimica, usos, etc.

Si contamos con todos los instrumentos necesarios, podemos estudiar la conformación interna de cada uno de los órganos, sus funciones y procesos. Por consiguiente, en el presente trabajo se plantearon las siguientes interrogantes:

¿Cómo es la morfología externa y la estructura interna de las especies de la familia Fabaceae Acacia visco o Piptadenia grata (vilca), Caesalpinia spinosa (tara) y Geoffroea decorticans (chañar)?

¿Existe similitud en la estructura externa e interna de las tres especies?

\section{OBJETIVO}

Determinar la estructura morfológica externa e interna de las fabáceas Acacia visco (vilca), Caesalpinia spinosa (tara) y Geoffroea decorticans (chañar).

\section{MATERIAL Y MÉTODOS}

\section{1) Área de Estudio}

La zona de estudio fue la provincia de Tacna departamento de Tacna y sus diez distritos que se encuentran en altitudes que oscilan entre los 374 m.s.n.m. (Sama) y 2935 m.s.n.m. (Palca), de clima templado, benigno y acogedor.

\section{2) Métodos de Trabajo}

\section{Colecta de Especimenes}

La colecta de material botánico comenzó en el mes de abril del 2006 y terminó en el mes de enero del 2007. Se esperó la época de floración de cada espécimen para proceder a colectar ramas con flores y frutos.

Se realizó un estudio detallado "in situ" de las tres especies y se colectó material para procesarlo en el laboratorio.

\section{Preparados Microscópicos}

Se realizaron cortes transversales, longitudinales, superficiales a mano alzada de acuerdo con el órgano en estudio de la planta, se colorearon con safranina. 
La falta de un micrótomo impidió observar claramente la anatomía del tallo y raíz, por lo cual en el presente trabajo no se consideró la estructura interna de estos órganos.

Se tomaron microfotografías y se esquematizaron las estructuras observadas.

\section{Identificación}

La identificación y descripción de los órganos vegetativos se hizo con ayuda de referencias bibliográficas pertinentes.

\section{RESULTADOS}

El estudio de las fabáceas Acacia visco (vilca), Caesalpinia spinosa (tara) y Geoffroea decorticans (chañar) se realizó durante el año 2006 a enero del 2007 en la provincia de Tacna, departamento de Tacna, Perú, llegando a establecer diferencias en cuanto a la mofologia externa y estructura interna, las cuales son las siguientes:

Acacia visco o Piptadenia grata (vilca) tiene el tallo de mayor longitud y diámetro que las otras dos especies, copa amplia, corteza castaño oscuro.

Las hojas son caducas o semipersistentes alternas, compuestas bipinnadas con 7 a 18 pares de foliolos de 8 a 10 $\mathrm{cm}$ de largo, cada uno con 25 a 35 pares de foliolulos de 4 a 7 $\mathrm{mm}$ de largo por 1 a 1,5 $\mathrm{mm}$ de ancho. Con glándulas en cada par de foliolos y en la base del peciolo.

La epidermis adaxial está revestida de cutícula delgada, mesófilo constituido por dos estratos de tejido parenquimático en empalizada y un estrato de tejido parenquimático lagunoso; en la epidermis abaxial se encuentran estomas anisociticos y anomociticos; tiene tricomas unicelulares pequeños.

Inflorescencia en glomérulos solitarios de 1,5 a $1,6 \mathrm{~cm}$ de diámetro que forman racimos axilares.

Flores hermafroditas actinomorfas, androceo con numerosos estambres, anteras versátiles, granos de polen tricolpados. Fruto en legumbre recta lineal comprimida de 7 a $16 \mathrm{~cm}$ de largo por $2 \mathrm{a} 3 \mathrm{~cm}$ de ancho, apergaminado.

Semillas de color café comprimidas ovaladas en número de 8 a 10 por fruto, de 8 a 10 mm de diámetro.

Caesalpinia spinosa (tara), árbol de copa irregular, con espinas cónicas cortas y fuertes de 2 a $7 \mathrm{~mm}$ de largo, corteza rugosa, gris ceniciento.

Hojas persistentes opuestas compuestas bipinnadas de 15 a $20 \mathrm{~cm}$ de largo con 2 a 3 pares de foliolos de 6 a $16 \mathrm{~cm}$ de largo, con 5 a 8 pares de foliolulos coriáceos subsésiles.

La epidermis está protegida por una cuticula delgada, mesófilo con un estrato de tejido parenquimático en empalizada y un estrato de tejido parenquimático lagunoso, con numerosos rafideos; estomas anomociticos.
Inflorescencia en racimos terminales de 16 a $25 \mathrm{~cm}$ de longitud; flores de 10 a $12 \mathrm{~mm}$ de largo, corola con cinco pétalos libres espatulados, androceo con 10 estambres, anteras subglobosas, versátiles, granos de polen tricolpados.

Gineceo ligeramente pubescente, ovario súpero, placentación marginal. Fruto en legumbre de 6 a $12 \mathrm{~cm}$ de largo por 1,5 a $2 \mathrm{~cm}$ de ancho, con 4 a 8 semillas orbiculares de color café, de 8 a $10 \mathrm{~mm}$ de diámetro.

Geoffroea decorticans (chañar), árbol de tronco verde parduzco, corte exfoliante amarillenta.

Hojas desiduas alternas compuestas imparipinnadas de 3 a $6 \mathrm{~cm}$ de largo, con 4 a 5 pares de foliolos oblongos y uno terminal siempre de mayor tamaño.

Epidermis adaxial delgada, mesófilo con un estrato de tejido parenquimático en empalizada y un estrato de tejido parenquimático lagunoso, estomas anomociticos, tricomas pluricelulares no ramificados. Inflorescencia en racimos corimbrosos cortos, flores zigomorfas de color amarillo con estrias rojas, corola pentámera, cáliz gamosépalo. Androceo de 5 a $6 \mathrm{~mm}$ de largo, anteras basifijas, granos de polen tricolpado.

Gineceo de pistilo simple filiforme de 5 a $10 \mathrm{~mm}$ de largo, ovario sủpero con un carpelo y un lóculo.

Fruto en drupa de 2 a $3 \mathrm{~cm}$ de largo, con 1 a 2 semillas naviculares.

\section{CONCLUSIONES}

1. En el presente estudio se concluye que existen diferencias morfológicas externas e internas en los órganos vegetativos y reproductores de Acacia visco, Caesalpinia spinosa y Geoffroea decorticans, las cuales se presentan en figuras, cuadros y fotografias.

\section{BIBLIOGRAFÍA}

Brako, L. \& J. Zarucchi. 1993. "Catalogue of the Flowering plants and gymnosperms of Perú". Missouri garden. Vol. 45 $1286 \mathrm{p}$.

Cortés F. 1980. "Histologia Vegetal Básica"Primera Edición. Editorial H. Blume. Ediciones-España.

Esau K. 1985. "Anatomia Vegetal" Primera Edición. Editorial Ediciones Omega S.A. Barcelona, España.

Fuller H. y Col. 1974. "Botánica" Quinta Edición. Editorial Interamericana S.A. México.

Ibarra Y. y Col. 2002. "Estudio Biosistemático Vegetal de la Familia Fabaceae de la Provincia de Tacna" Tacna.

Jones S. 1987. Sistemática vegetal. Primera Edición. Editorial Fuentes Impresores S.A. México.

Sagastegui A. Leiva. 1993. Flora invasora de los cultivos del Perú. Primera Edición. Trujillo, Perú. 


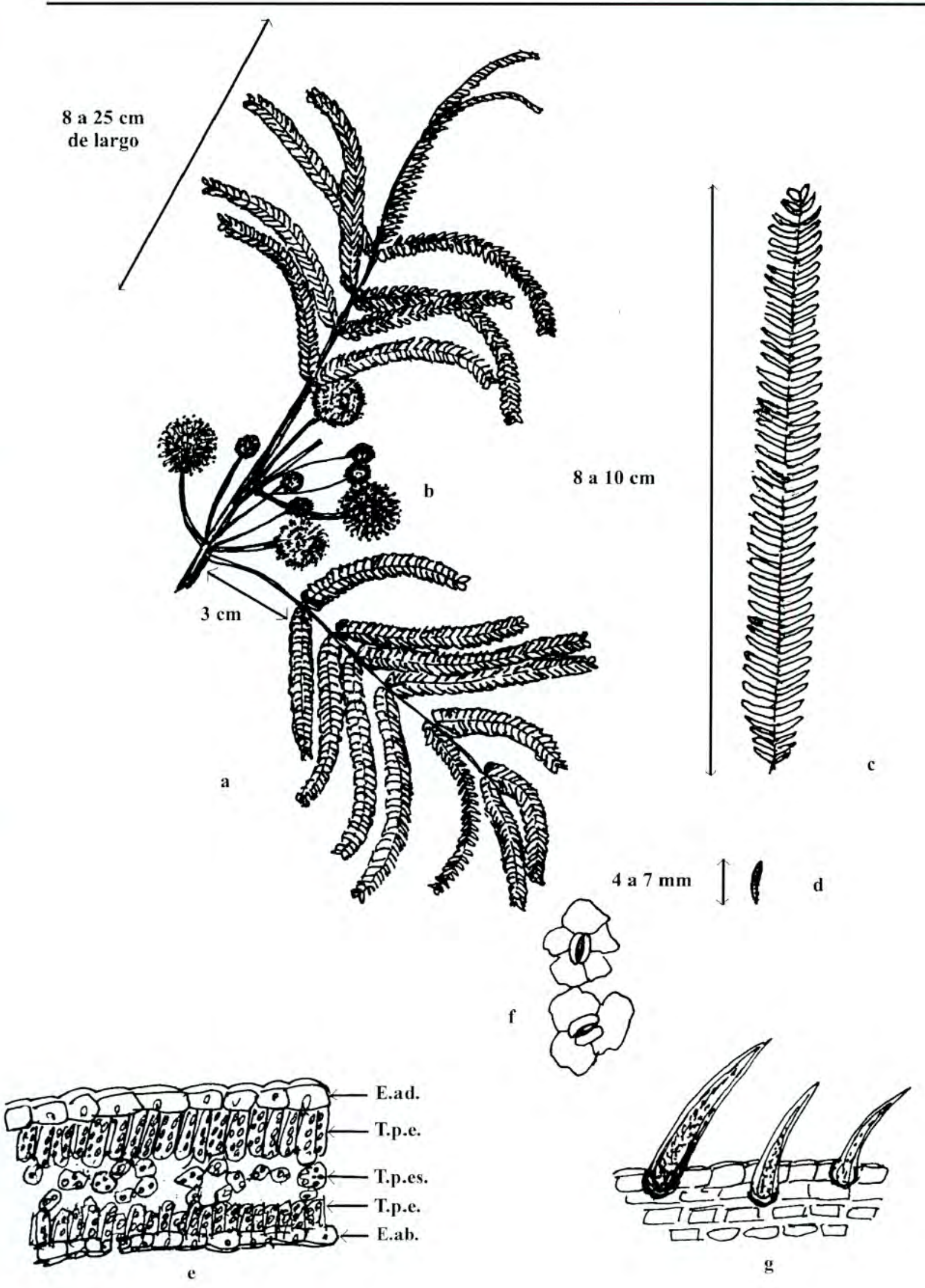

Figura $\mathrm{N}^{\circ}$ 1: Acacia visco (vilca). a) Hoja bipinnada b) Inflorescencia c) Foliolo (tamaño natural) d) Foliolulo (tamaño natural) e) Corte transversal de hoja: Ea (Epidermis adaxial) T.p.e. (Tejido parenquimático en empalizada) T.p.es. (Tejido parenquimático esponjoso) Eab (Epidermis abaxial) f) Estomas g) Tricomas unicelulares 

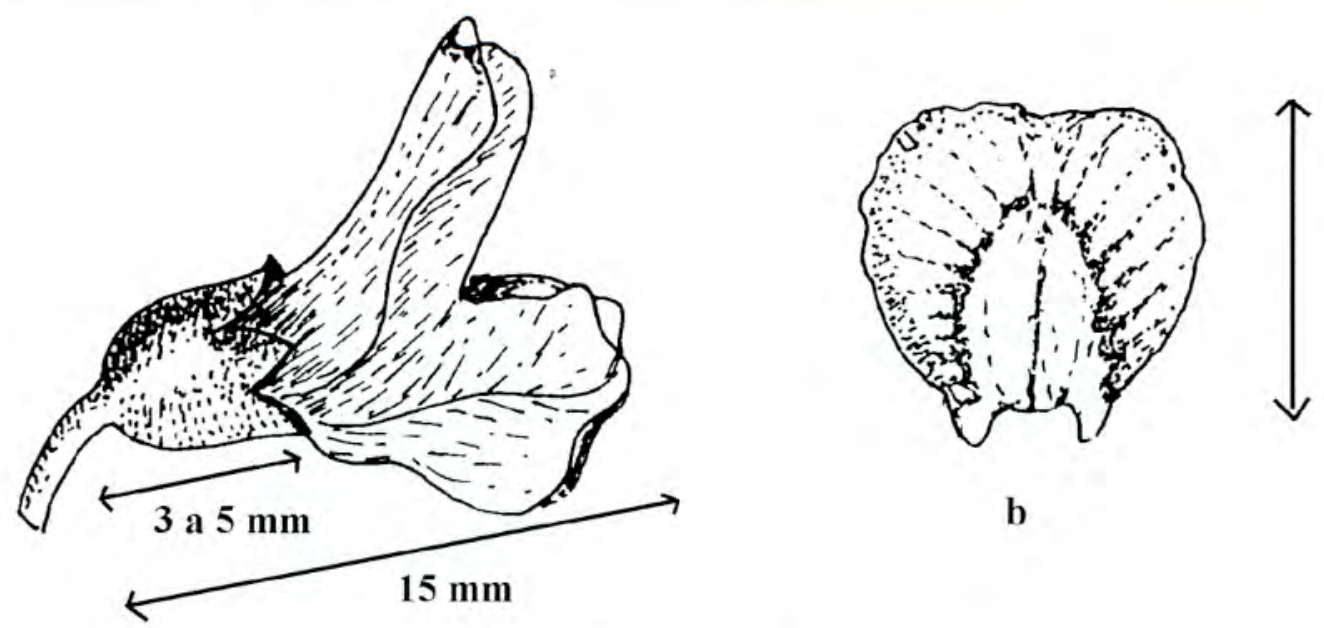

1 a $1,2 \mathrm{~cm}$

b

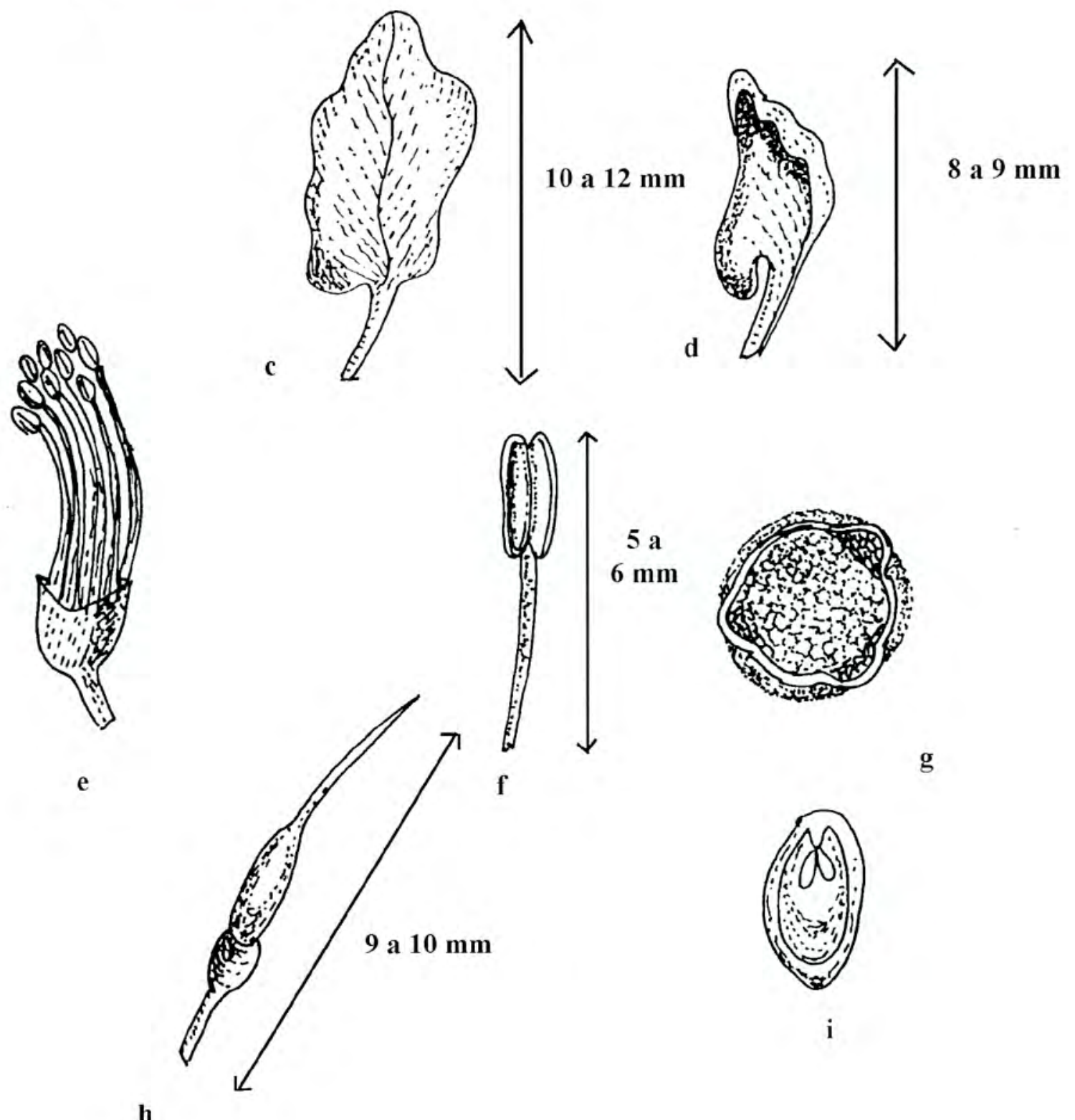

Figura $\mathrm{N}^{\circ} 2$ : Geofroea decorticans. a) Flor b) Pétalo estandarte c) Pétalo ala d) Pétalo quilla e) Androceo f) Estambre g) Grano de polen h) Gineceo i) Placentación marginal 